\title{
Behaviour and strength of FRP-strengthened RC structures: a state-of-the-art review
}

\author{
J. G. Teng, J. F. Chen, S. T. Smith and L. Lam
}

\section{T. Jessop, Magnox}

I would like to ask the authors Teng, Chen, Smith and Lam the following:-

I assume that for such strengthening methods to be successful the original structure has to be in good condition and in particular free of cracks. It has recently been my experience to adopt such a strengthening method, using CFRP plates, to strengthen a structure so that it could accept seismic loads.

A large wall with vertical cracks at mid-span, varying in width of up to $3 \mathrm{~mm}$ wide, had been declared capable of resisting a postulated seismic load. It was not straightforward to subsequently confirm, analytically, what influence the crack had on the wall's capacity for lateral loading. It was assumed that it was likely that the horizontal reinforcement had yielded across the crack and thus the basis of the strengthening scheme was to replace it with external reinforcement in the form of CFRP plates such that flexural capacity was restored. It was known that the crack's width was variable with temperature. CFRP plates were applied when the wall was 'cold' (with adjacent plant off-load) and the crack widths at their minimum value. On return to service of the plant the crack widths increased and one of the plates failed by bond failure between the adhesive and the concrete surface.

Initially the failure was attributed to poor workmanship in the surface preparation but subsequent investigation concluded that the plate bonding system would not be capable of resisting the high loads associated with the high strain induced in the plates across the crack by the crack widening. It was subsequently declared that, this being the case, plate bonding would not be a suitable repair/enhancement for structural elements subjected to flexure (seismic loads in our case) that contain significant cracks.

Have the authors come across such limitations in their research?

\section{Author's reply}

The authors would like to thank Mr Jessop for his interesting contribution.

For the successful application of the FRP bonding technique in practice, it is essential that all possible failure modes are properly considered in design. For flexural members strengthened with FRP plates bonded on the tension face, the possible failure modes include more conventional ones such as crushing of compressive concrete and FRP rupture, with or without the yielding of steel reinforcement. In addition, debonding failure modes which are unique to such plated members must be examined. The authors classified these debonding failure modes into 'plate end debonding' and 'intermediate crack-induced debonding'. The latter failure mode refers to debonding that starts from a flexural or a flexural-shear crack within the plated region and propagates towards a plate end. It may be important to note that this debonding failure mode can become critical in many cases. Further information on intermediate crack-induced debonding can be found elsewhere. ${ }^{3,48,82-84,133,134}$

From the contributor's description, the wall, which had major flexural cracks at mid-span and was subsequently strengthened with bonded FRP plates, failed under thermal loading by intermediate crack-induced debonding. A simple and safe strength model based on Chen and Teng's FRP-toconcrete bond strength model ${ }^{47}$ has been proposed for this failure mode. A more comprehensive description of the model with some modification will shortly be published. ${ }^{134}$ The effect of thermal loading on this failure mode can be easily understood by comparing the widening of the flexural crack due to thermal loading to that due to mechanical loading. Furthermore, if the stress in the plate due to thermal loading can be determined accurately, then it is not unreasonable to assume that this stress can be compared with that recommended in Teng et al.'s strength model ${ }^{48,134}$ to check the likelihood of debonding. However, no existing study has addressed explicitly the effect of thermal loading on intermediate crack-induced debonding.

Only a limited amount of research exists on the effect of precracking on the intermediate crack-induced debonding failure load ${ }^{12,135}$. Tests conducted on beams preloaded to cracking and then completely unloaded before the bonding of FRP plates suggest that such preloading (and precracking) has little effect on the failure load. While considerably more research must be undertaken to explore the effect of preloading (and precracking) on this and other failure modes, the authors' 
view is that the FRP bonding technique can certainly be applied to concrete structures with precracking, provided the effect of such precracking is understood and considered in design.

The case described by the contributor highlights the need for a great deal of further research in this important area.

\section{REFERENCES}

133. SEBASTIAN, W. M. Significance of mid-span debonding failure in FRP-plated RC beams. Journal of Structural Engineering, ASCE, 2001, 127, No. 7, 792-798.

134. Teng J. G., Smith S. T., Yao J. and Chen J. F. Intermediate crack-induced debonding in RC beams and slabs. Construction and Building Materials (in press).

135. RAHIMI, H. and Hutchinson, R. Concrete beams strengthened with externally bonded FRP plates. Journal of Composites for Construction, ASCE, 2001, 5, No. 1, pp. 44-56. 